[Agr. Biol. Chem., Vol. 32, No. 2, p. 144 -152, 1968]

\title{
Studies on the Fermentative Production of Purine Derivatives
}

\author{
Part I. Derivation of Guanosine and Inosine-Producing \\ Mutants from a Bacillus Strain
}

\author{
By Ikuo Nogami, Makoto Kida, Teiji IrJma* \\ and Masahiko YoNEDA \\ Microbiological Research Laboratories, Research and Development Division, \\ Takeda Chemical Industries, Ltd., Osaka, Japan \\ * Institute for Fermentation Osaka, Osaka, Japan
}

Received July 28, 1967

\begin{abstract}
By the application of various genetical techniques, a number of guanosine and inosineproducing mutants were obtained from a Bacillus strain. The indispensable genetic characters of the mutants concerning with guanosine productivity were adenine requirement, lack of GMP-reductase and mutation to adenine and adenosine resistance from adenine and adenosine sensitiveness. Main products of these mutants were guanosine and inosine. Their culture broths also contained hypoxanthine, xanthine and sometimes a little guanine and xanthosine. Furthermore a few unknown nucleosides were also detected. The yields of guanosine were about $5 \mathrm{mg} / \mathrm{ml}$ in 4 -day culture broths.
\end{abstract}

In recent years, studies on the fermentative production of nucleic acid-related substances have been conducted very actively. Although there are many reports concerning with the production of hypoxanthine ${ }^{1-71}$ or xanthine derivatives $^{8 \sim 11}$ by microbial mutants, it has not been reported that a large amount of guanine derivatives is accumulated in the culture fluid. Only Demain ${ }^{22}$ and Jackson

\footnotetext{
Abbreviations: ade-, adenine-requiring; his-, histidine-requiring; pur-, purine-requiring; $8 \mathrm{AG}^{r}$, 8azaguanine-resistant; red-, GMP-reductase-lacking; $\mathrm{AAR}^{s}$, adenine and adenosine-sensitive; $A \mathrm{AR}^{r}$, adenine and adenosine-resistant. A, adenine; $A R$, adenosine; $H x$, hypoxanthine; HR, inosine; $X$, xanthine; $X R$, xanthosine; $G$, guanine; $G R$, guanosine; $C$, cytosine; $\mathrm{CR}$, cytidine; U, uracil; UR, uridine; $\mathrm{T}$, thymine; TR, thymidine.

1) N. H. Giles and C. W. Partridge, Proc. Natl. Acad. Sci. U.S., 43, 305 (1957).

2) K. Uchida, A. Kuninaka, $H$. Yoshino and $M$. Kibi, Agr. Biol. Chem., 25, $80+$ (1961).

3) R. Aoki, H. Momose, Y. Kondo, N. Muramatsu and Y. Tsuchiya, J. Gen. Appl. Microbiol., 9, $387(1963)$.

4) T. Nara, M. Misawa, K. Nakayama and S. Kinoshita, Amino Acid and Nucleic Acid, 8, 94 (1963).
}

reported that an adenine auxotroph, derived from an adenine and xanthine auxotroph of Micrococcus glutamicus by back mutation, accumulated $5^{\prime}$-GMP and $5^{\prime}$-IMP in the culture fluid. But the yield of 5'-GMP was not so much. The authors obtained guanosine and inosine-producing mutants from a Bacillus strain. In this paper, the methods of derivation of the guanosine and inosine-producing

5) I. Nogami and S. Igarashi, Ann. Rep. Takeda Research Lab., 22, 99 (1963).

6) K. Nakayama, T. Suzuki, Z. Sato and S. Ki* noshita, $f$. Gen. Appl. Microbiol., 1o, 133 (1964).

7) T. Suzuki, I. Nogami, Y. Kitahara, M. Ishikawa and M. Yoneda, presented at the Meeting of Kansai Division of the Agricultural Chemical Society of Japan, Kyoto, Feb, 25, 1967.

8) B. Magasanik and M. S. Brooke, J. Biol. Chem., 206, 83 (1954).

9) M. Misawa, T. Nara, K. Udagawa, S. Abe and S. Kinoshita, Agr. Biol. Chem., 28, 690 (1964).

10) A. Imada, I. Nogami, Y. Nakao and S. Igarashi, Ann. Rep. Takeda Research Lab., 23, 54 (1964).

I1) M. Fujimoto, K. Uchida, M. Suzuki and H. Yoshino, Agr. Biol. Chem., 30, 605 (1966).

12) A. L. Demain and M. Jackson, Appl. Microbiol, 14, $821(1966)$ 
mutants and identification of the products of these mutants are described.

\section{MATERIALS AND METHODS}

Organism. Bacillus sp. No. 102 was newly isolated from soil and used as a parent strain in the following experiments. Induction of mutants was carried out by ultraviolet ray irradiation on spores. The genetic characters of the mutants were examined by replica plating method.

Media. The following media were used for the isolation of mutants and growth test. Complete medium (NA medium) was composed of Polypepton, $10 \%$; yeast extract, $0.20_{0}^{\circ} \mathrm{NaCl}, 0.2 \circ$; and the intial $\mathrm{pH}$ was adjusted to 7.2 . Mangalo's medium ${ }^{13}$ supplemented with thiamine hydrochloride, $3 \gamma / \mathrm{ml}$, and biotin, $2 \gamma / \mathrm{ml}$, was used as a minimal medium (Mu medium). For the solid medium, $20_{j}^{\circ}$ of agar was added. Seed medium for fermentation was composed of soluble starch, $20_{0}^{\circ}$; corn steep liquor, $20_{\circ}^{\circ} ; \mathrm{K}_{2} \mathrm{HPO}_{4}$, $0.3 \circ ; \mathrm{KH}_{2} \mathrm{PO}_{4}, 0.1 \%$; and adenine, $100 \mathrm{r} / \mathrm{ml}$. The initial $\mathrm{pH}$ was adjusted to 7.2 . Fermentation medium was composed of maltose, $10 \%$ (autoclaved separately); $\left(\mathrm{NH}_{4}\right)_{2} \mathrm{SO}_{4}, 2 \%$; dried yeast, $1 \% \% ; \mathrm{MgSO}_{4}$. $7 \mathrm{H}_{2} \mathrm{O}, 0.2 \% ; \mathrm{CaHPO}_{4}, 0.5 \% \mathrm{Ca}_{3}\left(\mathrm{PO}_{4}\right)_{2}, 0.5 \% ; \mathrm{CaCO}_{3}$, $2.0^{\circ}$; and biotin, $0.2 \gamma / \mathrm{ml}$. The $\mathrm{pH}$ was 7.6 without adjustment.

Fermentation conditions. After inoculating a loopful of cells into a 200-ml Erlenmeyer flask containing $20 \mathrm{ml}$ of the seed medium, the flask was incubated for $24 \mathrm{hr}$ on a rotary shaker at $37^{\circ} \mathrm{C}$. One $\mathrm{ml}$ of the seed growth was inoculated into a $200-\mathrm{ml}$ creased Erlenmeyer flask containing $20 \mathrm{ml}$ of the fermentation medium. Then the Hask was incubated for 4 days on the rotary shaker at $37^{\circ} \mathrm{C}$.

Growth test for mutants in the liquid medium. A loopful of cells was inoculated into $5 \mathrm{ml}$ of $\mathrm{NA}$ medium in a test tube. After incubation for $24 \mathrm{hr}$ on the reciprocal shaker, the cells were harvested by centrifugation. A cell suspension was made up in Mu medium at optical density of 0.250 in a Coleman Junior spectrophotometer at $660 \mathrm{~m} /$. One-tenth $\mathrm{ml}$ of the cell suspension was inoculated into $5 \mathrm{ml}$ of $\mathrm{Mu}$ medium supplemented with various nutrients. After incubation for $24 \mathrm{hr}$ on the reciprocal shaker at $37^{\circ} \mathrm{C}$, the cell growth was measured on optical density in the Coleman Junior spectrophotometer at $660 \mathrm{~m} /$.

13) R. Mangalo and J. T. Wachsman, J. Bacteriol., 83, $27(1962)$.
Transformation. Transformation was carried out with Spizizen's method, ${ }^{14}$ using DNA which was extracted from Bacillus subtilis IFO 3026 by Saito's method. ${ }^{15}$

Assays of produets. Culture broth was diluted tenfold with distilled water. Then the diluted broth was stood for $10 \mathrm{~min}$ in a boiling water bath and then centrifuged at $3000 \mathrm{rpm}$ for $15 \mathrm{~min}$. The products in the supernatant were assayed by the following methods. Hypoxanthine and inosine were determined with Kalcker's method, 16) by using xanthine oxidase ${ }^{17}$ and nucleoside phosphorylase.16) By utilizing nucleoside phosphorylase ${ }^{16}$ ) and the colorimetric method ${ }^{18}$, for the determination of guanine, guanosine was determined as follows. To $0.5 \mathrm{ml}$ of $0.25 \mathrm{M}$ phosphate buffer $(\mathrm{pH} 7.5$ ) containing $0.25 \mathrm{M}$ arsenate were added $0.5 \mathrm{ml}$ of a sample containing 0.05 to $0.20 \mu$ mole of guanosine and $0.5 \mathrm{ml}$ of nucleoside phosphorylase dissolved in $0.05 \mathrm{M}$ phosphate buffer ( $\mathrm{pH} 7.5)$. Two control systems were used. One of them was sample blank which contained $0.05 \mathrm{M}$ phosphate buffer ( $\mathrm{pH} 7.5$ ) instead of enzyme. The other was enzyme blank which contained water instead of sample. After incubation at $37^{\circ} \mathrm{C}$ for $120 \mathrm{~min}$, to each tube was added $1.0 \mathrm{ml}$ of $8 \%$ $\mathrm{Na}_{2} \mathrm{CO}_{3}$ in $0.25 \mathrm{~N} \mathrm{NaOH}$. After standing for $10 \mathrm{~min}$, to each tube was added $0.5 \mathrm{ml}$ of Folin-Ciocalteu reagent (acidity, $1 \mathrm{~N}$ ) and the tubes were incubated at $37^{\circ} \mathrm{C}$ for $20 \mathrm{~min}$. Optical density was read at $625 \mathrm{~m} \mu$. The amount of guanosine in the sample was calculated from standard curve of guanine. Purines and their nucleosides were also determined by paper electrophoresis. On Whatman No. 1 filter paper, it was carried out in $0.025 \mathrm{M}$ borate buffer ( $\mathrm{pH} \mathrm{9.5)} \mathrm{for} 60 \mathrm{~min}$ at $2 \mathrm{kV} / 36 \mathrm{~cm}$. In this manner, four natural purines and their nucleosides could be completely separated. After drying the filter paper, the bands of these substances were cut off and eluted with $0.01 \mathrm{~N} \mathrm{HCl}$ or $0.2 \mathrm{M}$ phosphate buffer $(\mathrm{pH} 7.0$ ) for $10 \mathrm{~min}$ in a boiling water bath. The amounts of these substances were determined spectrophotometrically by measuring absorbance at $260 \mathrm{~m} \mu$. Maltose

14) J. Spizizen, Proc. Natl. Acad. U.S., 44, 1072 (1958).

15) H. Saito and K. Miura, Biochem. Biophys. Acta, 72, 619 (1963).

16) H. M. Kalcker, J. Biol. Chem., 167, 429, 461, 477 (1947).

17) B. L. Horecker and L. A. Heppel, ibid., 178, $683(1949)$.

18) G. H. Hichings, ibid., 139, $843(1941)$ 
was determined by the method of Somogyi.19)

Identification of products. After treatment with active charcoal, the products in broth were separated by 1 modification of the procedure of Anderson. ${ }^{20}$ ) Merely $0.6 \mathrm{M}$ sodium acetate was used instead of grading $0.6 \mathrm{M}$ sodium acetate linearly to $2 \mathrm{M}$ sodium acetate for the elution. After treatment with active charcoal, each fraction of chromatogram was tested on ultraviolet-absorbing curve, mobility in paper electrophoresis, $R f$ value of paper chromatography21, and determination of ribose. ${ }^{22}$;

Reagents. Purines, pyrimidines, their nucleosides and Folin-Ciocalteu reagent were purchased from Wakô Pure Chemical Industries, Ltd.

\section{RESULTS}

1) Inosine Productivities of Various adeMutants and Selection of Starting Strain

As shown in Table $I$, the ade mutants directly derived from parent strain (Bacillus sp. No. 102) accumulated a mixture of hypoxanthine and inosine in the culture broths. But an ade ${ }^{-}$mutant (strain G3-46 in Fig. 1) of $8 \mathrm{AG}^{r}$ strain derived from the same parent strain produced much more inosine than hypoxanthine. Total amount of purines accumulated by G3-46 was more than that by other ade ${ }^{-}$mutants. This mutant was used as the starting strain in the following experiments. Strain 46-22 was obtained by a single colony isolation of G3-46. Histidine-requiring marker was added to $46-22$ in order to detect the contaminants of other ade ${ }^{-}$mutants in the following experiments (see Fig. 1 and Table I).

2) Guanosine Productivities of ade $^{-}$Mutants Possessing or Lacking GMP-Reductase

It has not been reported that ade mutant, obtained by one step mutation, accumulates guanine derivatives in the culture broth. As shown in Table $I$, in our strain, the products of the ade ${ }^{-}$mutants were almost hypoxanthine

19) M. Somogyi, J. Biol. Chem., 195, 19 (1955). 20) N. G. Anderson and F. C. Radd, Biochim. Biophys. Acta, 55, 275 (1962).

21) R. Markham and J. D. Smith, Biochem. J., 49, 401 (1951).

22) W. Mejbaum, Z. Physiol. Chem., 258, 117 (1939).
TABle I. InOSINe Production of Various ade- MUTANTS

\begin{tabular}{|c|c|c|c|c|}
\hline \multirow{2}{*}{ Strain } & \multirow{2}{*}{ Genotype } & \multicolumn{3}{|c|}{ Productivity ( $\mathrm{mg}, \mathrm{ml})$} \\
\hline & & $\mathrm{Hx}$ & HR & GR \\
\hline 136 & ade- & 3.1 & 5.0 & 1.0 \\
\hline 287 & ade- & 3.2 & 5.6 & 0.3 \\
\hline 680 & ade- & 1.2 & 0.7 & 0.9 \\
\hline 702 & $\mathrm{ade}^{-}$ & 2.5 & 5.2 & 0.8 \\
\hline 703 & ade- & 4.3 & 0.7 & 0.6 \\
\hline 749 & ade- & 3.8 & 6.6 & 1.4 \\
\hline 753 & $\mathrm{ade}^{-}$ & 2.2 & 3.7 & 0.3 \\
\hline G3-46 & 8AGr $\mathrm{ade}^{-}$ & 1.6 & 11.7 & 1.0 \\
\hline $46-22$ & $8 \mathrm{AG}^{r} \mathrm{ade}^{-}$ & 0.0 & 13.1 & 1.4 \\
\hline 22-H5 & 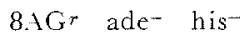 & 2.0 & 10.9 & 1.4 \\
\hline
\end{tabular}

Cultivation was carried out for 4 days at $37^{\circ} \mathrm{C}$.

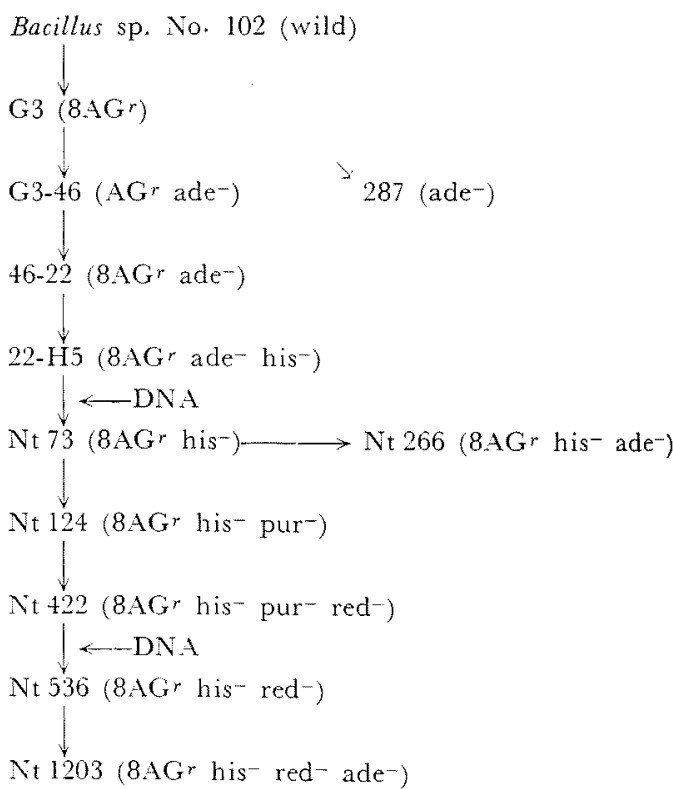

FIG. 1. Derivation of ade- Mutants Possessing or Lacking GMP-Reductase.

Inside of parenthesis indicates genotype of mutant. DNA indicates the process of transformation. Mutation was carried out by UV-irradiation.

derivatives and a little guanosine. Considering from the metabolic pathway of purine, ${ }^{231}$ it seems likely that guanosine productivity of

23) B. Magasanik and D. Karibian, J. Biol. Chem., 
bacterial mutant concerns with the existence of GMP-reductase. Then, the ade ${ }^{-}$mutants possessing or lacking GMP-reductase were obtained by the process as shown in Fig. 1. In Fig. 1, strain Nt 266 is a representative ade ${ }^{-}$ mutant possessing GMP-reductase, while strain Nt 1203 is the one lacking GMP-reductase. Table II shows the comparison between the

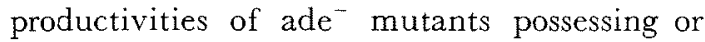
lacking GMP-reductase. From the viewpoint of the guanosine productivity, ten of each ade $^{-}$mutant were selected from fifty of each ade $^{-}$mutant as indicated in Table II. In

Table II. Guanosine Production by adeMUTANTS POSSESSING OR LACKING GMP-REDUCTASE
GMP-reductase Productivity $(\mathrm{mg} / \mathrm{ml})$

Strain $\mathrm{Hx}$ HR GR

Nt $149 \quad 0.5 \quad 9.3 \quad 1.4$

Nt $152 \quad 0.0 \quad 10.5 \quad 1.5$

$\begin{array}{lllll}\text { Nt } 156 & 0.0 & 10.3 & 1.2\end{array}$

$\begin{array}{llll}\text { Nt } 187 & 0.0 & 6.1 & 1.2\end{array}$

$\begin{array}{lllll}\text { Nt } 191 & 0.2 & 4.8 & 1.4\end{array}$

$\begin{array}{llll}\text { Nt 25l } & 0.3 & 2.5 & 1.3\end{array}$

$\begin{array}{llll}\text { Nt } 256 \quad 1.4 & 10.0 & 1.9\end{array}$

$\begin{array}{llll}\text { Nt } 258 & 0.0 & 7.7 & 1.3\end{array}$

$\begin{array}{llll}\text { Nt } 266 & 0.0 & 13.1 & 2.4\end{array}$

$\begin{array}{llll}\mathrm{Nt} 268 & 1.2 & 3.5 & 1.3\end{array}$
GMP-reductase Productivity $(\mathrm{mg} / \mathrm{ml})$

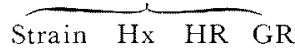

Nt $1196 \quad 0.0 \quad 11.9 \quad 2.9$

Nt $1198 \quad 0.0 \quad 12.4 \quad 3.3$

Nt $1199 \quad 0.0 \quad 14.12 .8$

Nt $1203 \quad 0.6 \quad 11.8 \quad 3.2$

Nt $1207 \quad 0.0 \quad 11.2 \quad 2.5$

Nt $1209 \quad 2.0 \quad 5.7 \quad 2.6$

Nt $1247 \quad 1.0 \quad 10.3 \quad 2.9$

Nt $1249 \quad 0.4 \quad 7.2 \quad 2.1$

Nt $1254 \quad 0.0 \quad 11.9 \quad 3.1$

Nt $1256 \quad 1.2 \quad 12.0 \quad 2.6$
Cultivation was carried out for 4 days at $37^{\circ} \mathrm{C}$.

this result, it is appreciable that the guanosine productivities of the mutants lacking GMPreductase are higher than those of the mutants possessing GMP-reductase.

3) Derivation and Properties of Adenine and Adenosine-Sensitive (AAR ${ }^{8}$ ) Mutants

As mentioned above, the mutants lacking GMP-reductase were more suitable for guanosine production than those possessing it. However, such mutants in which enzymes participating in purine metabolic pathway were merely blocked were not so adequate to produce much more guanosine. As shown in Fig. 2, the mutants which cannot grow on $\mathrm{Mu}$ plate containing each $0.1 \mathrm{~mm}$ adenine and adenosine were obtained from strain $\mathrm{Nt} 422$ (pur ${ }^{-}$, red $^{-}$) by ultraviolet ray irradiation. These mutants could be divided into two types. One of them lost the ability to deaminate adenine derivatives. The other was inhibited by adenine and adenosine in its growth (strain Nt508 in Fig. 2). Strain Nt 647 (AAR $^{s}$, pur ${ }^{+}$) was derived from Nt 508 $\left(\mathrm{AAR}^{s}\right.$, pur ${ }^{-}$) by transformation. And then various ade ${ }^{-}$mutants were obtained from $\mathrm{Nt}$ 647. Table III shows the hypoxanthine derivatives productivities of such mutants. The productivities became much less than those

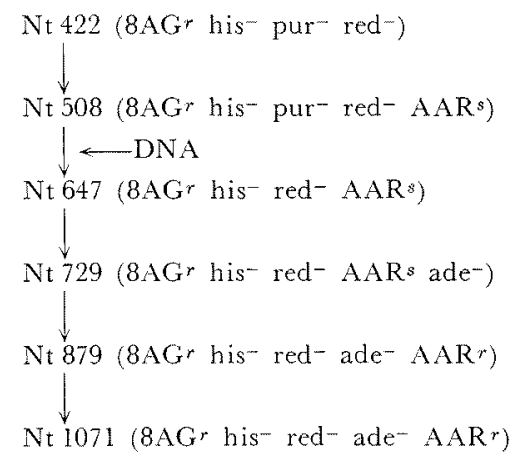

FIG. 2. A Process of Derivation of Guanosine and Inosine-Producing Mutant.

Inside of parenthesis indicates genotype of mutant. DNA indicates the process of transformation. Mutation was carried out by UV-irradiation.

TABLE III. INOSINE PRODUCTION BY AARs ade- Mutants

\begin{tabular}{|c|c|c|c|c|c|c|c|}
\hline \multirow{2}{*}{ Strain } & \multirow{2}{*}{\multicolumn{4}{|c|}{ Genotype }} & \multicolumn{3}{|c|}{$(\mathrm{mg} / \mathrm{ml})$} \\
\hline & & & & & $\mathrm{Hx}$ & $\mathrm{HR}$ & GR \\
\hline $22-\mathrm{H} 5$ & $8 \mathrm{AGr}$ & $\mathrm{ade}^{-}$ & his- & & 2.1 & 9.9 & 0.6 \\
\hline Nt 729 & $8 \mathrm{AG}^{r}$ & $h_{\text {is }}^{-}$ & AARs & $\mathrm{ade}^{-}$ & 2.4 & 1.4 & 1.6 \\
\hline Nt 730 & $"$ & " & $"$ & $n$ & 0.0 & 0.0 & 0. \\
\hline Nt 731 & " & $"$ & $"$ & " & 0.0 & 0.0 & 0. \\
\hline Jt 732 & $" \prime$ & " & " & " & 0.2 & 0.0 & 0. \\
\hline Nt 733 & $"$ & " & $"$ & $"$ & 1.0 & 0.0 & 0. \\
\hline Nt 734 & " & $n$ & $"$ & $"$ & 1.0 & 4.0 & 2. \\
\hline $\mathrm{Nt} 736$ & " & $"$ & $"$ & $"$ & 0.0 & 0.0 & 0. \\
\hline t 738 & $"$ & " & " & " & 0.0 & 0.0 & 0. \\
\hline t 739 & $"$ & " & $"$ & $" \prime$ & 0.0 & 0.0 & \\
\hline 741 & " & " & $n$ & " & 0.0 & 0.0 & 0. \\
\hline
\end{tabular}

Cultivation was carried out for 4 days at $37 \% \mathrm{C}$. 

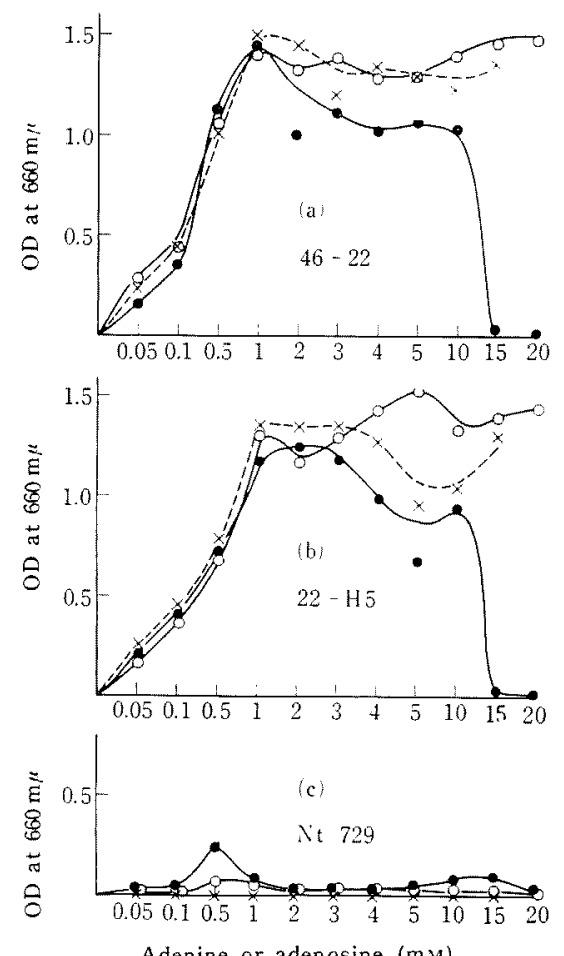

FIG. 3. Growth Response of Normal ade- Mutants and $\mathrm{AAR}^{s}$ ade- Mutant to Adenine and Adenosine.

Cultivations was carried out for $24 \mathrm{hr}$ at $37^{\circ} \mathrm{C}$ in $\mathrm{Mu}$ medium supplemented with $70 \% / \mathrm{ml}$ of histidine. (a), 46-22 (8AGr ade (b) $^{-}$(b), 22- $\mathrm{H} 5$

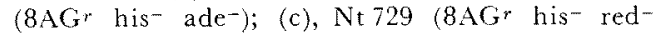
$\mathrm{AAR}^{s}$ ade $\left.{ }^{-}\right)$- - , adenine; $\bigcirc-O$, adenosine; $x \ldots \times$, adenine plus adenosine ( $\mathrm{mM}$ as total adenine).

of normal ade mutant (strain 22-H5). In order to examine the properties of the ade-, $\mathrm{AAR}^{s}$ mutant (strain Nt729), the growth response of ade ${ }^{-}, \mathrm{AAR}^{8}$ mutant and normal ade $^{-}$mutants to adenine and adenosine was tested (Fig. 3). Strains 46-22 and 22-H5, which are normal ade mutants, were not inhibited by adenosine or adenine plus adenosine, so far as examined, and by $10 \mathrm{~mm}$ adenine. On the other hand, $\mathrm{AAR}^{s}$, ade mutant ( $\mathrm{Nt} 729$ ) could scarcely grow on adenine or adenosine in $\mathrm{Mu}$ medium. Merely in $0.5 \mathrm{~mm}$ adenine it could grow a little. In the
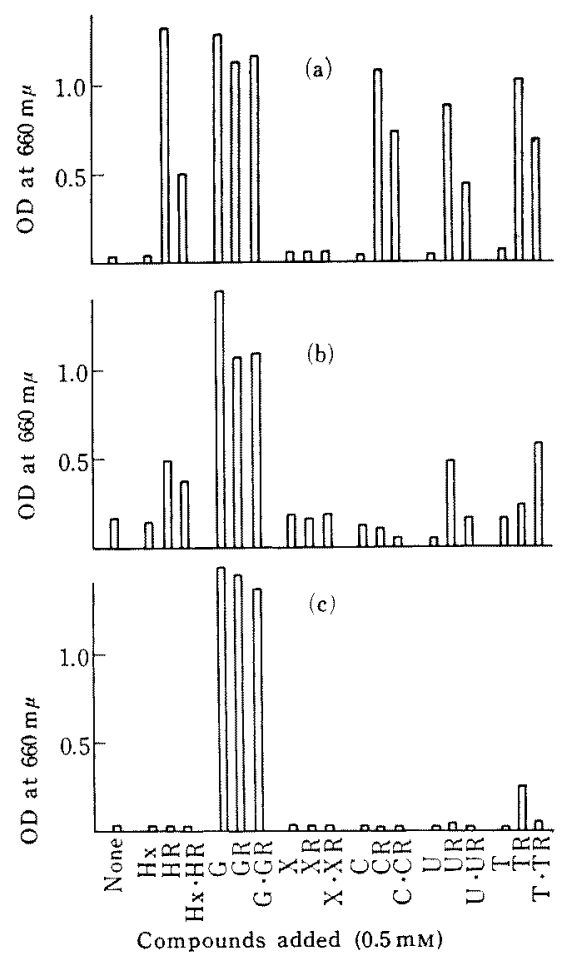

FIG. 4. Reversal of Adenine and Adenosine Inhibition.

Nt $729\left(8 \mathrm{AG}^{r}\right.$ his $^{-} \mathrm{red}^{-} \mathrm{AAR}^{8}$ ade-) was used. Cultivation was carried out for $24 \mathrm{hr}$ at $37^{\circ} \mathrm{C}$ in Mu medium supplemented with $70 \gamma / \mathrm{ml}$ of histidine. (a), inhibition by $2 \mathrm{mM}$ adenine; (b), inhibition by $2 \mathrm{mM}$ adenosine; (c), inhibition by $1 \mathrm{mM}$ adenine plus $1 \mathrm{~mm}$ adenosine. Presentation as $\mathrm{Hx} \cdot \mathrm{HR}$ indicates $0.25 \mathrm{~mm}$ hypoxanthine plus $0.25 \mathrm{~mm}$ inosine.

growth inhibition by $2 \mathrm{~mm}$ adenine, $2 \mathrm{~mm}$ adenosine and $1 \mathrm{~mm}$ adenine plus $1 \mathrm{~mm}$ adenosine, the reversal of the growth by addition of purines, pyrimidines and their nucleosides was examined. As shown in Fig. 4, the growth inhibition by adenine, adenosine or adenine plus adenosine was completely revers" ed by guanine or guanosine, while partially by thymidine. The inhibition by $2 \mathrm{~mm}$ adenine or $2 \mathrm{~mm}$ adenosine could be overcome completely or partially by inosine. The addition of cytidine or uridine could also reverse the inhibition by $2 \mathrm{~mm}$ adenine. On the basis 
of the above observations, it may be suggested that adenine and adenosine suppress the formation of or inhibit the activity of enzymes on the purine biosynthetic pathway to IMP and from IMP to GMP in the $\mathrm{AAR}^{8}$, ade mutant (Nt 729). In other words, the mutant, in which feedback control mechanism in purine biosynthetic pathway has been disturbed, may be found in the $\mathrm{AAR}^{r}$ mutants derived from the $\mathrm{AAR}^{3}$, ade ${ }^{-}$mutant (Nt 729).

4) Guanosine Productivities of AAR $r$ Mutants Derived from Nt 729 (AAR ${ }^{s}$, ade $^{-}$)

Many mutants which can grow on $\mathrm{Mu}$ medium containing adenine or adenosine in various concentrations were obtained from $\mathrm{Nt} 729\left(\mathrm{AAR}^{s}\right.$, ade $\left.{ }^{-}\right)$. And hypoxanthine derivatives and guanosine productivities of such mutants were examined. Table IV shows a

Table IV. Guanosine Production By AAR $r$ Mutants DERIVED FROM NT 729

\begin{tabular}{|c|c|c|c|c|c|}
\hline \multirow{2}{*}{ Strain } & \multirow[b]{2}{*}{ A, AR in plate } & \multicolumn{4}{|c|}{ Productivity $(\mathrm{mg} / \mathrm{ml})$} \\
\hline & & $\mathrm{Hx}$ & $\mathrm{HR}$ & GR & $\mathrm{X}$ \\
\hline Nt 729 & & 2.8 & 0.8 & 1.1 & 1.1 \\
\hline Nt 877 & A $5 \mathrm{mM}$ & 1.5 & 3.9 & 2.0 & 0.7 \\
\hline Nt 879 & " & 1.0 & 5.5 & 2.3 & 0.9 \\
\hline Nt 881 & $"$ & 8.1 & 0.0 & 1.2 & \\
\hline Nt 889 & $"$ & 6.8 & 0.0 & 2.1 & \\
\hline Nt 891 & $"$ & 4.6 & 1.5 & 1.7 & \\
\hline Nt 1072 & AR $20 \mathrm{~mm}$ & 3.3 & 9.9 & 1.5 & \\
\hline Nt 1073 & " & 1.3 & 6.8 & 2.0 & \\
\hline Nt 1074 & $"$ & 1.1 & 2.9 & 1.3 & \\
\hline Nt 1579 & $\mathrm{~A}, \mathrm{AR} 20 \mathrm{~mm}$ each & 1.5 & 6.3 & 2.7 & \\
\hline Nt 1580 & $"$ & 1.4 & 8.8 & 2.4 & \\
\hline Nt 1586 & $"$ & 2.0 & 8.7 & 2.7 & \\
\hline
\end{tabular}

Cultivation was carried out for 4 days at $37^{\circ} \mathrm{C}$. Xanthine was estimated by paper electrophoresis.

part of the results. The amount of hypoxantine derivatives or guanosine which was produced by these resistant mutants varied with the mutant used. For example, the production of hypoxanthine derivatives by strain Nt 1072 attained to the level of normal ade $^{-}$mutant (22-H5). Guanosine productivity of strain $\mathrm{Nt} 879$ exceeded that of $\mathrm{Nt} 729$. Examining the growth response of $\mathrm{Nt} 879$ to adenine and adenosine in Mu medium, Nt 879 was still more sensitive to adenosine than normal ade $^{-}$mutant (22-H5) (Fig. 5a).
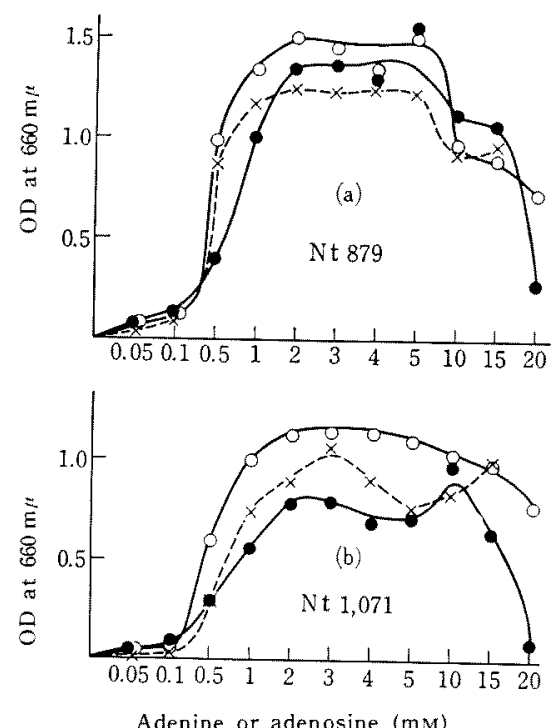

FIG. 5. Growth Response of AARr Mutants to Adenine and Adenosine.

Cultivation was carried out for $24 \mathrm{hr}$ at $37^{\circ} \mathrm{C}$ in $\mathrm{Mu}$ medium supplemented with $70 \% / \mathrm{ml}$ of histidine. (a), Nt 879 (8AGr his ${ }^{-}$red $^{-}$AAR $^{r}$ ade $^{-}$); (b), Nt 1071 (8AGr his- red- AARr ade-); $-O$, adenine; $-\mathrm{O}_{-}$, adenosine; -- $\times \ldots-.-$, adenine plus adenosine ( $\mathrm{m} M$ as total adenine).

Table V. Guanosine Production By AaR $r$ Mutants Derived from Nt 879

Conc. of

Strain A, AR in plate

Productivity

St 879
A, AR in plate

Nt 879

Nt 1062

$\mathrm{Nt} 1063$

AR $20 \mathrm{~mm}$

Nt 1065

Nt 1067

Nt 1068

Nt 1069

Nt 1071

Nt 1569

Nt 1574

Nt 1575
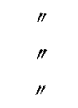

"r

"

(mg/ml)

$\begin{array}{rrr}\text { Hx } & \text { HR } & \text { GR } \\ 1.0 & 5.1 & 2.2 \\ 1.4 & 5.0 & 4.0 \\ 1.1 & 7.2 & 2.8 \\ 1.7 & 6.2 & 3.2 \\ 1.6 & 7.6 & 2.5 \\ 1.1 & 6.9 & 2.4 \\ 1.0 & 10.0 & 3.4 \\ 1.5 & 3.3 & 5.4 \\ 1.5 & 5.7 & 2.8 \\ 1.5 & 6.9 & 3.3 \\ 2.0 & 5.7 & 3.7\end{array}$

Cultivation was carried out for 4 days at $37^{\circ} \mathrm{C}$. 
Furthermore, the mutants which became more resistant to adenosine were obtained from Nt 879. As shown in Table $V$. such mutants could accumulate much more guanosine in the culture broths than could $\mathrm{Nt} 879$. Especially, more than $5 \mathrm{mg} / \mathrm{ml}$ of guanosine was accumulated by strain $\mathrm{Nt} 1071$ at 4-day culture. The growth response of $\mathrm{Nt} 1071$ to adenine and adenosine in $\mathrm{Mu}$ medium is shown in Fig. 5b. The degree of resistance to adenosine of $\mathrm{Nt} 107 \mathrm{I}$ was higher than that of $\mathrm{Nt} 879$. However, the growth of $\mathrm{Nt} 1071$ became poorer than that of $\mathrm{Nt} 879$ in Mu medium.

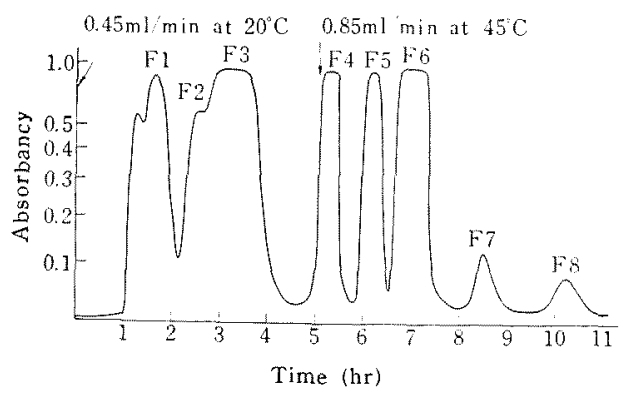

FIG. 6. Separation of $\mathrm{Nt}_{\mathrm{t}} 1071$ Products on Dowex-1 $\times 8$.

The products of Nt 1071 were analysed by using $4 \mathrm{ml}$ of the broth. After treatment with active charcoal, the products of $\mathrm{Nt} 107 \mathrm{I}$ were chromatographed on a column $(1.0 \times 150 \mathrm{~cm}) \mathrm{con}$ taining Dowex- $1 \times 8$ ion-exchange resin $(400$ mesh, acetate form). Elution was carried out with $0.6 \mathrm{~N}$ acetate buffer ( $\mathrm{pH} 4.4$ ). UV-absorbance of each fraction was recorded at $253 \mathrm{~m} \mu$ by a Uvicord (LKB type 470la, Sweden).

\section{5) Identification of Products of Nt 1071}

After treatment of 4-day culture broth of Nt 1071 with active charcoal, the products were separated by column chromatography using Anderson's method (Fig. 6). Judging from the elution pattern, F3, F4, F5, F6, F7 and $F 8$ corresponded to inosine, hypoxanthine, xanthine, guanosine, guanine and xanthosine, respectively. After each fraction was collected and treated with active charcoal, paper

TABLE VI. PAPER Electrophoresis AND PAPER ChROMATOGRAPHY

\begin{tabular}{|c|c|c|c|}
\hline \multirow{2}{*}{ Substance } & \multicolumn{2}{|c|}{$\begin{array}{c}\text { Mobility }(\mathrm{cm}) \text { in } \\
\text { P.E.P. }\end{array}$} & \multirow{2}{*}{$\begin{array}{l}\text { Rf Value } \\
\text { in P.C. }\end{array}$} \\
\hline & $\mathrm{pH} 9.5$ & $\mathrm{pH} 2.2$ & \\
\hline Adenine & 1.6 & 23.3 & 0.22 \\
\hline Adenosine & 8.3 & 16.9 & 0.20 \\
\hline Hypoxanthine & 10.0 & 9.6 & 0.39 \\
\hline Inosine & 15.3 & 4.3 & 0.48 \\
\hline Xanthine & 13.7 & 2.5 & 0.27 \\
\hline Xanthosine & 18.2 & 3.4 & 0.34 \\
\hline Guanine & 3.3 & 16.8 & 0.25 \\
\hline Guanosine & 12.0 & 7.8 & 0.41 \\
\hline$F_{3}$ & 15.4 & 4.0 & 0.47 \\
\hline $\mathrm{F} 4$ & 10.1 & 9.2 & 0.38 \\
\hline F5 & 14.0 & 2.6 & 0.26 \\
\hline F6 & 12.0 & 7.8 & 0.41 \\
\hline F7 & 3.2 & 16.4 & 0.26 \\
\hline F8 & 18.4 & 3.3 & 0.35 \\
\hline
\end{tabular}

P.C. indicates paper chromatography. Solvent system, isopropanol: saturated ammonium sulfate: water $=2: 79: 19$.

P.E.P. indicates paper electrophoresis. $\mathrm{pH} 2.2$, 1.250 formic acid in $3.9 \%$ acetic acid: pH 9.5, $0.025 \mathrm{M}$ borate buffer.

\begin{tabular}{|c|c|c|c|c|c|c|c|}
\hline \multirow{2}{*}{ Fraction } & \multicolumn{6}{|c|}{ TABLE VII. UV-SPECTRAL DATA } & \multirow[b]{2}{*}{ Type } \\
\hline & $\mathrm{pH}$ & $i \max$ & $\lambda \min$ & $250 / 260$ & $280 / 260$ & $290 / 260$ & \\
\hline F3 & $\left\{\begin{array}{r}2 \\
7 \\
12\end{array}\right.$ & $\begin{array}{l}247.5 \\
246.5 \\
252.0\end{array}$ & $\begin{array}{l}221.0 \\
220.0 \\
223.5\end{array}$ & $\begin{array}{l}1.66 \\
1.75 \\
1.15\end{array}$ & $\begin{array}{l}0.22 \\
0.23 \\
0.15\end{array}$ & $\begin{array}{l}0.03 \\
0.03 \\
0.03\end{array}$ & Inosine \\
\hline $\mathrm{F} 4$ & $\begin{array}{r}2 \\
7 \\
12\end{array}$ & $\begin{array}{l}246.5 \\
248.0 \\
258.0\end{array}$ & $\begin{array}{l}217.0 \\
221.0 \\
231.0\end{array}$ & $\begin{array}{l}1.56 \\
1.33 \\
0.85\end{array}$ & $\begin{array}{l}0.06 \\
0.10 \\
0.09\end{array}$ & $\begin{array}{l}0.01 \\
0.01 \\
0.01\end{array}$ & Hypoxanthine \\
\hline F5 & $\begin{array}{r}\frac{2}{7} \\
12\end{array}$ & $\begin{array}{l}263.0 \\
267.0 \\
278.0\end{array}$ & $\begin{array}{l}237.0 \\
237.0 \\
254.0\end{array}$ & $\begin{array}{l}0.63 \\
0.69 \\
0.96\end{array}$ & $\begin{array}{l}0.37 \\
0.67 \\
1.92\end{array}$ & $\begin{array}{l}0.04 \\
0.17 \\
1.32\end{array}$ & Xanthine \\
\hline F6 & $\begin{array}{r}2 \\
7 \\
12\end{array}$ & $\begin{array}{l}252.0 \\
252.0 \\
256 \sim 265\end{array}$ & $\begin{array}{l}223.5 \\
222.0 \\
229.0\end{array}$ & $\begin{array}{l}1.16 \\
1.20 \\
0.90\end{array}$ & $\begin{array}{l}0.67 \\
0.66 \\
0.53\end{array}$ & $\begin{array}{l}0.35 \\
0.25 \\
0.08\end{array}$ & Guanosine \\
\hline
\end{tabular}

pH 2, 0.01 N HCl: pH 7, 0.2 M phosphate buffer; pH 12, $0.01 \mathrm{~N} \mathrm{NaOH}$. 
chromatography and paper electrophoresis were carried out. From these results (Table VI), F3, F4, F5, F6, F7 and F8 corresponded to inosine, hypoxanthine, xanthine, guanosine, guanine and xanthosine, respectively. Table VII shows the ultraviolet spectral data of each fraction except for F7 and F8. These results show that the ultraviolet absorption spectrum of F3, F4, F5 and F6 agreed with that of inosine, hypoxanthine, xanthine and guanosine, respectively. Molar ratio of base to ribose in F3 and F6 approximated 1. Although details have not been studied, F1 and F2 were mixtures of unknown nucleosides.

\section{6) Time Course of Production by Nt 1071}

Time course of production of purines and purine nucleosides by $\mathrm{Nt} 107 \mathrm{l}$ is given in Fig. 7. In accordance with the consumption of sugar, guanosine, inosine and hypoxantine, respectively, were produced in the culture broth. Inosine and guanosine reached to the maximal yields at 3 days and 4 days, re-
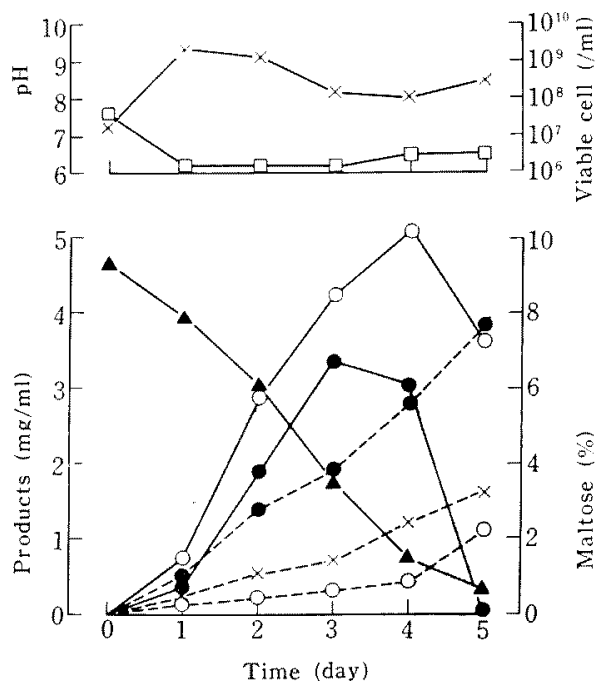

FIG. 7. Time Course of Fermentation of Nt 1071.

Cultivation was carried out at $37^{\circ} \mathrm{C}$. Purines and their nucleosides were quantitatively determined by paper electrophoresis.

$-\times-$, viable cell; - $\square-, \mathrm{pH} ;-\bigcirc-$, guanosine; - - - inosine; --.-., hypoxanthine; -... $x$-... xanthine; -.-.-.-, guanine; -- - maltose, spectively. And then the nucleosides were degraded to the corresponding free bases. Xanthine also began to be accumulated at the early stage in the fermentation.

\section{DISCUSSION}

Accumulation of hypoxanthine $e^{1 \sim 71}$ derivatives in the culture fluid by mutants lacking adenylosuccinate synthetase has been widely observed in various organisms. In those cases, xanthine and guanine derivatives have not been accumulated. This fact may indicate that the feedback control mechanism in purine biosynthetic pathway which was described by Levin and Magsanik ${ }^{241}$ exists generally in various microorganisms. Nelson and White ${ }^{25 !}$ reported that the growth of a strain of Streptococcus pyogenes was inhibited by adenine in the synthetic medium and that the inhibition could be overcome by addition of other natural purines. On the other hand, in our $\mathrm{AAR}^{*}$ strain, its growth inhibition by adenine and adenosine could be overcome particularly by guanine or guanosine. (Fig. 4) The observation may indicate that adenine and adenosine suppress the formation of or inhibit the activity of enzymes in purine biosynthetic pathway from IMP to GMP in this strain. It was reported ${ }^{26}$ t that the activity of XMPaminase in $E$. coli was inhibited by adenosine and AMP. From the results of Table III and Fig. 4 , also in purine biosynthetic pathway to IMP, similar event may occur in our $\mathrm{AAR}^{8}$ strain. Furthermore, in the guanosine and inosine-producing mutants, the feedback control mechanism in purine biosynthetic pathway may be disturbed. However, these problems should be solved at enzymatic level.

Momose et al..$^{27}$ reported that, in the pur-

24) A. P. Levin and B. Magasanik, J. Biol. Chem, 236, $184(1960)$.

25) J. R. Nelson and A. G. C. White, Proc. Soc. Exptl. Biol. Med., 107, 242 (1961).

26) S. Udaka and H. S. Moyed, J. Biol. Chem., 238, 2797 (1963).

27) H. Momose, H. Nishikawa and N. Katsuya, J. Gen. Appl. Microbiol., 11, 211 (1965). 
strain lacking GMP-reductase which was derived from Bacillus subtilis Marburg strain, the growth was inhibited by guanosine. But, in our pur ${ }^{+}$strain lacking GMP-reductase (strain Nt 536 in Fig. 1), the growth was not inhibited by guanosine. Though using G3-46, which accumlated inosine rather than hypoxanthine, as the starting strain, the guanosine and inosine-producing mutant ( $\mathrm{Nt} \mathrm{1071)} \mathrm{accumulated}$ much hypoxanthine together with inosine and guanosine in the culture broth. In the order of xanthosine, inosine and guanosine, the nucleosides were ready to be degraded to the corresponding free bases in the culture broth.
Especially there was scarcely any xanthosine in the culture broth and, if any, it was just a little.

Acknowledgements. The authors wish to express deep thanks to Dr. R. Takeda and Mr. Y. Ishida of Research Laboratories, Takeda Chemical Industries, Ltd., and Dr. T. Hasegawa of Institute for Fermentation Osaka for their interest and encouragement. The skilful technical assistance of $\mathrm{Mr}$. T. Sakane and Mr. H. Watanabe is gratefully acknowledged. 